\title{
Reliability of 3D measurement of pelvic and lower limb kinematics during two single leg landing tasks
}

\author{
Grzegorz Szlachta $^{1,2}$, Rafał Gnat ${ }^{1,2}$, Maciej Biały ${ }^{1}$ \\ 1 Institute of Physiotherapy and Health Sciences, The Jerzy Kukuczka Academy of Physical Education, Katowice, Poland; \\ 2 Motion Analysis Laboratory, The Jerzy Kukuczka Academy of Physical Education, Katowice, Poland
}

\begin{abstract}
Study aim: Three-dimensional (3D) motion analysis is one of the available methods used to evaluate body kinematics. The aim of this study was to assess the intrarater reliability of measurement of pelvic and lower limb kinematics during two single leg landing tasks using 3D motion analysis.

Material and methods: 19 healthy volunteers ( 8 women, $11 \mathrm{men}$, age $23.1 \pm 2.8$ years, weight $70.7 \pm 9.2 \mathrm{~kg}$, height $174.8 \pm 6.7 \mathrm{~cm}$ ) performed five repeated single leg hurdle hops (SLHH) (30 cm height) and five single leg drop landings (SLDL) from a box (40 cm height) in one measurement session with a 15-minute break and after marker replacement with 3D assessment. The intraclass correlation coefficient (ICC), standard error of measurement (SEM), and the smallest detectable differences (SDD) were used to examine the reliability of kinematic parameters during the landing phase.

Results: The average intrarater ICC for SLHH was $0.92\left(\mathrm{SEM}=1.69^{\circ}, \mathrm{SDD} 4.68^{\circ}\right)$ and for $\mathrm{SLDL}$ was $0.96\left(\mathrm{SEM}=0.81^{\circ}\right.$, $\left.\mathrm{SDD}=2.26^{\circ}\right)$. After marker replacement ICC decreased to an average value of $0.81\left(\mathrm{SEM}=2.05^{\circ}, \mathrm{SDD} 5.68^{\circ}\right)$ for $\mathrm{SLHH}$ and $0.82\left(\mathrm{SEM}=2.36^{\circ}, \mathrm{SDD} 6.53^{\circ}\right)$ for $\mathrm{SLDL}$.

Conclusions: Using the 3D method to evaluate pelvis and lower limb kinematics during single leg landing in one measurement session is a high reliability method for most parameters. Marker replacement is one of the factors that reduce the reliability of measures. When applying the SEM and SDD values, which the present paper contains, it is worth mentioning that the obtained results are caused by measurement error or they are due to individual issues.
\end{abstract}

Keywords: Reliability - Landing - Kinematics - Pelvis - Lower extremity

\section{Introduction}

Abnormalities in many movement patterns such as landing, pivoting, running, and decelerating are linked with lower extremity injury. One of the most serious is anterior cruciate ligament (ACL) injury. About $60 \%$ of ACL injuries are connected with a noncontact mechanism $[13,17$, $19,25,31,34]$. Literature on the subject reports that about $90 \%$ of patients with ACL injury undergo reconstruction, mainly within the age range of $18-35$ years. Despite the surgery, they are at risk of ipsilateral and contralateral ACL injury where the reinjury rate is $15 \%[7,39]$.

Kinematics of the lower limb is one of the modifiable risk factors of ACL injury [17, 34]. The most frequently used parameter to assess knee kinematics in the 2-dimensional (2D) method is frontal plane projection angle (FPPA) $[14,15,28]$. It is defined as one of the main risk factors of ACL injury, which relates to approximately 50\% of noncontact injuries [19]. Research papers report a strong correlation of FPPA between 2-dimensional (2D) and 3-dimensional (3D) methods during standing $(\mathrm{r}=0.64)$, single leg squat $(r=0.78)$ [14] and single leg drop landing $(r=0.72)$ [35]. However, FPPA is not only associated with one plane of movement or with one joint. It consists of a combination of hip internal rotation and adduction, knee external rotation and abduction $[9,10,12,13,19,26$, $31,40]$. Researchers also distinguish kinematic risk factors of ACL injury, such as decreased knee and hip flexion, decreased plantar flexion, and increased foot pronation $[3,8,18,23,37]$. Single leg landing is mentioned as the one of the movement patterns during which the ACL gets injured [8]. Many screening tests have been used to assess lower limb kinematics, such as single leg squat, single leg landing, double leg landing, cutting, running and stepping tasks $[1,2,4,9,10,15,16,24,28-31,38]$. 
3D $[1,2,4,10,11,30,31,38]$ and 2D [14-16, 25, $28,29]$ methods are most frequently used for evaluation of the lower limb kinematics during these tests. 3D motion analysis is considered the gold standard when it comes to assessing kinematics of lower limb motion. Nevertheless, given the financial, temporal, spatial and accessibility factors, it is not applied by clinicians $[15,25,28]$. The 2D method is cheaper, portable, easy to use and more available, but it has limitations. For instance, it cannot measure kinematics in planes that are not perpendicular to the camera [15]. When performing motion analysis it is important to establish the reliability of the measurement tools used for analysis. Measurement error values allow one to determine whether the measurement results indicate the error or are related to the individual subject [2].

Currently, only a limited number of research reports assess the reliability of pelvis and lower limb kinematics using 3D motion analysis methods of single leg landing. Most studies focus on lower limbs and do not examine pelvis kinematics, which appears to have a significant connection with lower limb movement. The present study aimed to examine whether the 3D kinematic parameters of pelvis and lower limb joints show high reliability within a session and after marker replacement during two singleleg landing tasks.

\section{Materials and methods}

\section{Participants}

Nineteen healthy volunteers (11 men, 8 women) participated in this study. Subjects' mean age was $23.1 \pm 2.8$ years, mean body mass $70.7 \pm 9.2 \mathrm{~kg}$, mean body height $174.8 \pm 6.7 \mathrm{~cm}$, and mean body mass index (BMI) $23.1 \pm 1.8 \mathrm{~kg} / \mathrm{m}^{2}$. Participants were recruited for testing by completing the qualifying questionnaire. The inclusion criteria were: no history of serious pain and injury within the lumbo-pelvic area and lower limbs, no history of any surgical intervention in lumbo-pelvic area and lower limbs, no pain of the lumbo-pelvic area and lower limbs on the day of measurement, possibility of free palpation of the anterior and posterior superior iliac spines, medial and lateral epicondyles of the femur and medial and lateral malleolus, age between 18 and 35 years [39]. The exclusion criteria were as follows: any pain occurring during measurement which prevented continuing the test, and the subject withdrawing consent to participate in the tests. All subjects signed their written informed consent. The research was approved by the local Research Ethical Committee (No. 3/2017).

\section{Procedures}

The 6-camera motion analysis system BTS Smart (BTS Bioengineering, Milan, Italy) was used to record the marker position in $3 \mathrm{D}$ at $60 \mathrm{~Hz}$ frequency. The $15 \mathrm{~mm}$ diameter reflective markers for motion capture were applied on double-sided adhesive tape, protected by Kinesio Tape. The subject's lower limb was chosen randomly (7 left and 12 right limbs were assessed). The subjects were standing straight in the frame mounted on the floor in order to standardize foot placement. In total, 8 markers were placed on: anterior and posterior superior iliac spines on the left and right side, medial and lateral epicondyles of the femur, medial and lateral malleolus. Marker placement complied with recommendations of the International Society of Biomechanics [42]. Additionally, 3 markers were placed on the shoe, on the first and fifth metatarsal heads and heel, with the aim of determining the initial ground contact moment during landing.

\section{Single leg hurdle hop}

Participants performed 5 single leg hurdle hop (SLHH) tasks over the $30-\mathrm{cm}$ high hurdle, landing in the landing frame $(35 \mathrm{~cm} \times 15 \mathrm{~cm})$ situated $100 \mathrm{~cm}$ away from the take-off frame $(35 \mathrm{~cm} \times 15 \mathrm{~cm})$. The hurdle was located half way between the take-off frame and the landing frame. The static trial position was collected to designate the subject's neutral (zero) alignment; subsequent kinematic measures were related back to this position. After static registration recorded when the subject was standing in the take-off frame (Figure 1A), the SLHH was performed by bending the assessed hip and knee in the air, balancing on the contralateral foot (Figure 1B), then jumping forward over the hurdle and landing in the landing frame, holding the landing position for a minimum of $2 \mathrm{~s}$ (Figure 1C). Subjects kept their arms crossed against the chest and did not receive any instructions on the landing technique [31]. For example, to perform an SLHH on the right lower limb, the participants were instructed to take off from the left lower limb and land on the right limb in the landing frame. Trials were repeated if the participants stepped over the hurdle instead of jumping, knocked the hurdle down, were unable to hold the landing or supported on the contralateral leg. Before the registration, each subject performed 3 trial landings. The interval between landings lasted 1 minute.

\section{Single leg drop landing}

Participants performed 5 single leg drop landing (SLDL) tasks from a $40 \mathrm{~cm}$ high wooden box. From the moment when the subject was on the box in the take-off frame $(35 \mathrm{~cm} \times 15 \mathrm{~cm})$ with arms crossed on the shoulders, static registration was performed to designate the subject's neutral (zero) alignment (Figure 2A). After having the static registration recorded, the SLDL was performed by stretching their assessed limb in the air, at the height of the box, and balancing on the contralateral foot (Figure $2 \mathrm{~B})$, then leaning forward and falling freely from the box and landing on the landing frame $(35 \mathrm{~cm} \times 15 \mathrm{~cm})$ situated 


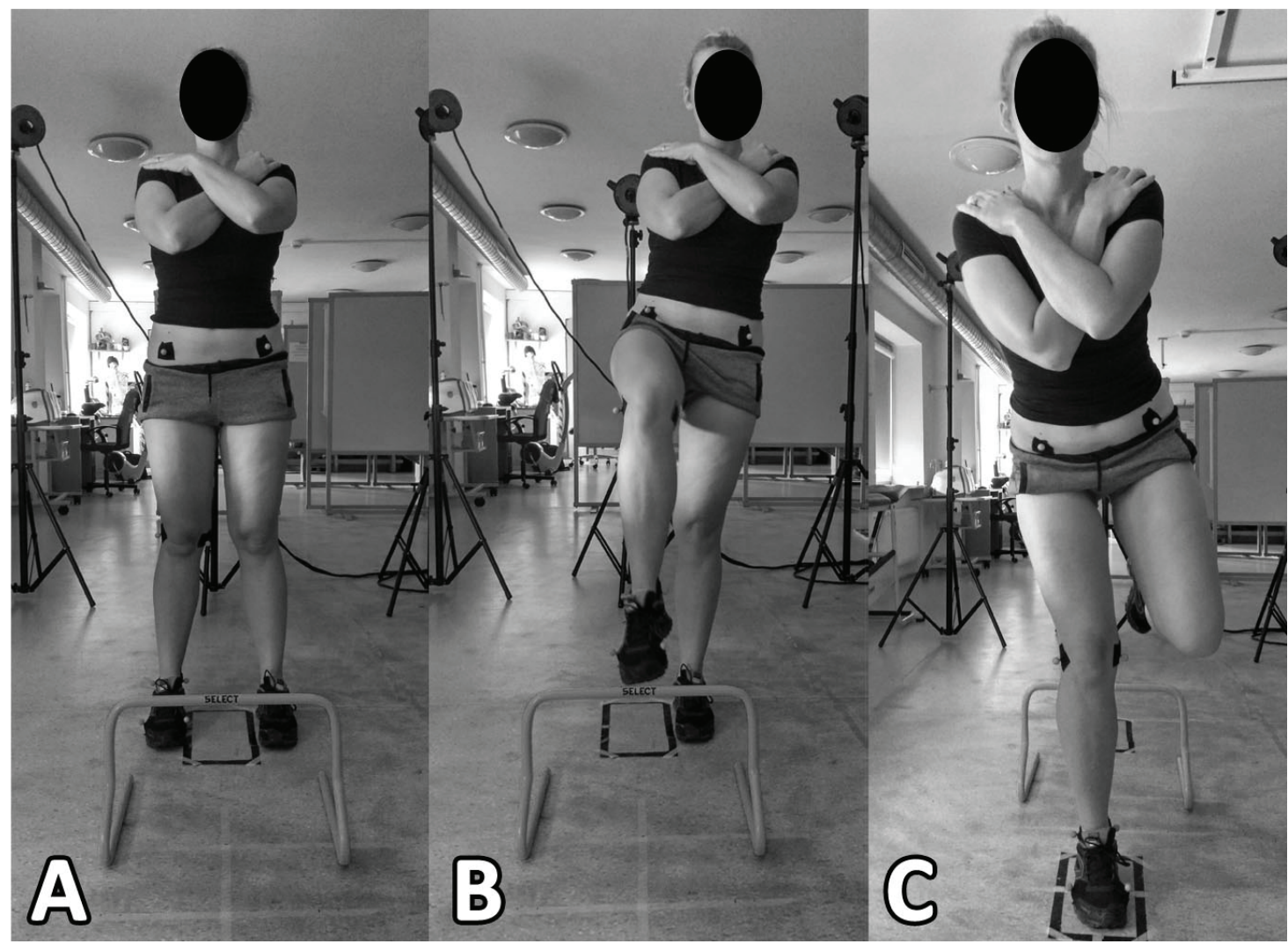

Figure 1. Illustration of the single leg hurdle hop task: (A) the static position, (B) take-off position, (C) landing phase.

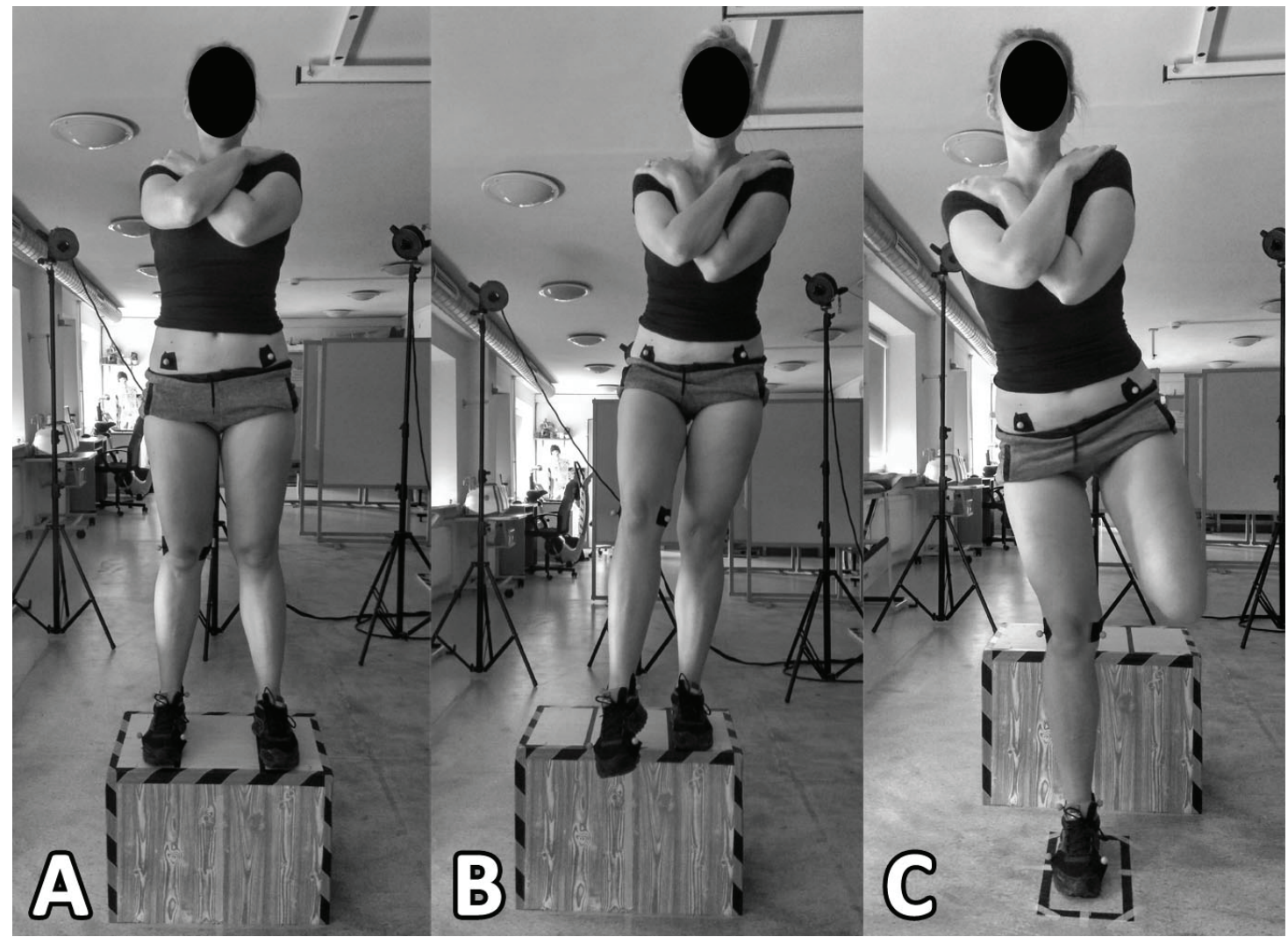

Figure 2. Illustration of the single leg drop landing task: (A) the static position, (B) take-off position, (C) landing phase 


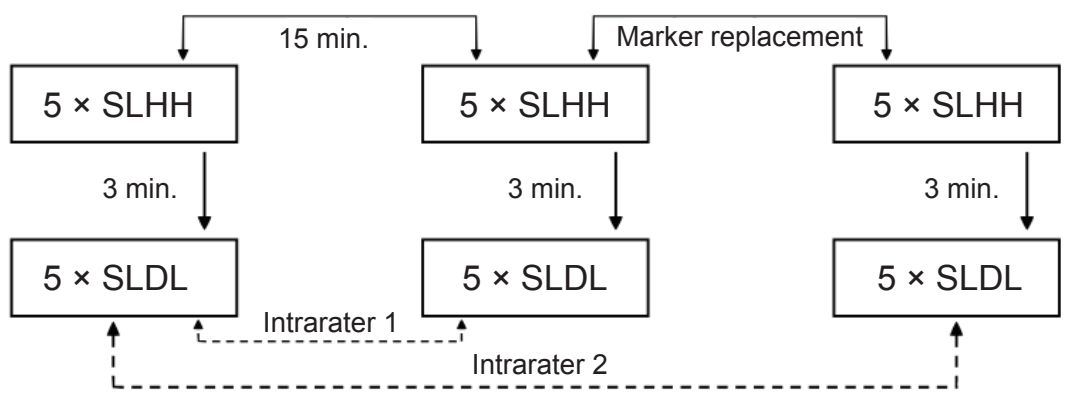

Figure 3. Schematic illustration of the measurement arrangement. 5xSLHH -5 repeated registrations of single leg hurdle hop; $5 \times$ SLDL -5 repeated registrations of single leg drop landing; intrarater 1 - reliability between series 1 and 2 ; intrarater $2-$ reliability between series 1 and 3

$15 \mathrm{~cm}$ away from the box [22], and holding the landing for a minimum of $2 \mathrm{~s}$ (Figure 2C). For example, to perform an SLDL on the right lower limb, participants were instructed to kick their right foot forward off the box in the air. While the right foot was in this position, the participant fell freely from the box from the left lower limb, landing on the right foot in the frame. Subjects did not receive any instructions on the landing technique [31]. Trials were repeated if participants stepped off the box instead of dropping, or were unable to hold the landing or support on the contralateral leg. Before the registration, each subject performed 3 trial landings. The interval between landings lasted 1 minute.

\section{Structure}

After marker placement, the subject performed a 10-minute warm-up on a cycloergometer; intensity was set at $50 \mathrm{~W}$ with $60 \mathrm{rpm}$. After the warm-up, the participant performed the first series of $5 \mathrm{SLHH}$, and after a 3-minute break, the subject performed 5 SLDL. There was a 15-minute interval between the first and second SLHH and SLDL series. After the second series, the markers were removed from the subject and placed again. After marker replacement, the subject performed the third SLHH and SLDL series (Figure 3). Static calibration was performed before each series [11].

\section{Data processing}

The landing phase was defined as the time from initial ground contact based on markers placed on the shoe to $100 \mathrm{~ms}$ after the initial contact $[20-22,36]$. The local coordinate system for pelvis, thigh, shank and foot was created in accordance with International Society of Biomechanics recommendations [41, 42]. Marker trajectories were filtered through a low-pass Butterworth filter at a cutoff frequency of $12 \mathrm{~Hz}[10,11]$. The hip joint center was calculated on the basis of the Bell approach, the knee joint center was set halfway between medial and lateral epicondyles of the thigh and the ankle joint center was set halfway between the medial and lateral malleolus $[5,6]$.
The Euler angle was calculated with the assumption that the $\mathrm{Z}$ axis (flexion/extension, dorsiflexion/plantar flexion) was the first rotation, the $\mathrm{X}$ axis (abduction/adduction, eversion/inversion) the second and the $\mathrm{Y}$ axis (internal/ external rotation) the third $[32,43]$. Obtained data were standardized, and the positive values were assigned to flexion, adduction, internal rotation of the hip and knee joint, and dorsiflexion and eversion of the ankle joint. To assess a pelvic movement, the Euler angle was calculated for pelvis displacement relative to the global (laboratory) coordinate system. A positive $\mathrm{Z}$ axis value was assigned to anterior pelvic tilt (lowering of anterior superior iliac spines' line in relation to posterior superior iliac spines line). A positive $\mathrm{X}$ axis value was assigned to ipsilateral lift (elevating the side of the pelvis, depending on the contralateral side to which the subject performs the landing, for example elevation of the right side of the pelvis, when the subject is performing right leg landing). A positive $\mathrm{Y}$ axis value was set to pelvis rotation towards the tested limb (e.g. right pelvis rotation when the subject performed landing on the right leg) [4, 27].

\section{Statistical analysis}

The reliability of each individual kinematic parameter was established using the intraclass correlation coefficient (ICC) and 95\% confidence intervals (CI). The ICC (3.5) model was applied based on the average of five measurements, comparing results from 1 vs 2 (intrarater 1) and 1 vs 3 measurement series (intrarater 2). In addition, the standard error of measurement $\left(\mathrm{SEM}=\mathrm{SD} \times(1-\mathrm{ICC})^{1 / 2}\right)$ along with the smallest detectable difference $\left(\mathrm{SDD}=\mathrm{SEM} \times 1.96 \times 2^{1 / 2}\right)$ was calculated. Based on the ICC value, the reliability was interpreted as follows: poor, less than 0.5 ; moderate, 0.5 to 0.75 ; good, 0.75 to 0.9 ; and excellent, greater than 0.9 [33]. Statistica version 13.0 software (StatSoft, Tulsa, United States of America), SPSS 18 (IBM Company, Armonk, United States of America) and Excel 2016 (Microsoft, Redmond, United States of America) were used in the analysis. 


\section{Results}

\section{SLHH results}

The intrarater 1 reliability of the pelvis and lower limb kinematics during SLHH based on the ICC value for most parameters was $>0.90$; only ICC for pelvis rotation kinematics was 0.59 . The SEM value was $<1.44^{\circ}$ (for pelvis rotation it was $8.89^{\circ}$ ) and SDD was $<3.99$ (for pelvis rotation it was $24.65^{\circ}$ ). After marker replacement (intrarater 2), the ICC decreased to $>0.84$ except knee internal/ external rotation, where the ICC was 0.65 , and ankle eversion/inversion, where the ICC was 0.04 . The SEM was $<3.34^{\circ}$ and SDD was $<9.24^{\circ}$ for all parameters (Table 1 ).

\section{SLDL results}

The intrarater 1 ICC during SLDL was $>0.90$ for all parameters. The SEM value was $<1.43^{\circ}$ and SDD was $<3.97^{\circ}$. After marker replacement (intrarater 2), the ICC decreased to $>0.75$ except ankle eversion/inversion, where the ICC was 0.25. The SEM value was $<5.54^{\circ}$ and SDD was $<15.36^{\circ}$ for all parameters (Table 2 ).

\section{Discussion}

The purpose of this study was to determine the reliability of pelvis and lower limb kinematics using the 3D method during SLHH and SLDL tasks. The current findings indicate that reliability during both tasks is excellent except pelvic rotation movement during SLHH, where reliability was moderate. The moderate reliability of pelvic rotation before marker replacement in this study may be caused by factors such as reference static alignment or different landing technique $[1,11]$. Noteworthy is the fact that after marker replacement this parameter showed excellent reliability.

Current reports indicate that the ICC generally decreased after marker replacement. The largest decrease was observed in ankle eversion/inversion, where the reliability was poor during both tasks, and for knee internal/ external rotation, where the reliability was moderate during SLHH. The other parameters showed good and excellent reliability. Marker replacement error could have been one of the factors that lowered reliability for many of the parameters during SLHH and SLDL $[1,11]$.

Other authors observed moderate to excellent reliability applying the 3D method within a session during drop vertical jump (ICC: 0.93-0.99) [11], single leg landing (ICC: 0.53-0.98) [1], single leg squat (ICC: $0.78-0.97$ ), cutting (ICC: 0.63-0.96) and running tasks (ICC: 0.63-0.94) [2]. They also noted a decline in reliability between sessions during drop vertical jump (ICC: 0.60-0.92) [11], single leg landing (ICC: $0.48-0.96$ ), single leg squat (ICC: $0.48-0.94$ ) [1], cutting (ICC: $0.42-0.83$ ) and running (ICC: $0.51-0.72$ ) tasks [2]. When assessing FPPA using the 2D method, the authors observed moderate to good reliability within a session during drop jump (ICC: 0.83-0.88) [28], single leg landing (ICC: $0.75-0.87$ ) $[15,28]$ and single leg squat (ICC: $0.59-0.86)[14,15,28]$. In some cases, the reliability increased between sessions during drop jump (ICC: 0.89-0.91) [28], single leg landing (ICC: $0.80-0.87$ )

Table 1. Intraclass correlation coefficient (ICC) (with 95\% confidence interval (CI)), standard error of measurement (SEM) and the smallest detectable differences (SDD) for kinematic parameters of pelvis and lower limb during single leg hurdle hop task

\begin{tabular}{lcccccc}
\hline & \multicolumn{2}{c}{ Intrarater 1 } & \multicolumn{3}{c}{ Intrarater 2 } \\
\hline & ICC $( \pm 95 \%$ CI $)$ & SEM $\left({ }^{\circ}\right)$ & SDD $\left({ }^{\circ}\right)$ & ICC $( \pm 95 \%$ CI $)$ & SEM $\left(^{\circ}\right)$ & SDD $\left(^{\circ}\right)$ \\
\hline Pelvic lift/drop & $0.90(0.73-0.96)$ & 1.21 & 3.35 & $0.93(0.83-0.97)$ & 1.04 & 2.87 \\
Pelvic rotation & $0.59(-0.07-0.84)$ & 8.89 & 24.65 & $0.97(0.93-0.99)$ & 2.33 & 6.45 \\
Pelvic ant./post. tilt & $0.97(0.93-0.99)$ & 0.87 & 2.40 & $0.93(0.81-0.97)$ & 1.31 & 3.64 \\
Hip add./abd. & $0.91(0.76-0.96)$ & 1.22 & 3.37 & $0.88(0.68-0.95)$ & 1.36 & 3.76 \\
Hip int./ext. rotation & $0.96(0.89-0.98)$ & 1.44 & 3.99 & $0.85(0.61-0.94)$ & 3.06 & 8.47 \\
Hip flex./ext. & $0.97(0.92-0.99)$ & 1.24 & 3.45 & $0.93(0.82-0.97)$ & 1.92 & 5.34 \\
Knee add./abd. & $1.00(0.99-1.00)$ & 0.00 & 0.00 & $0.96(0.90-0.99)$ & 1.96 & 5.42 \\
Knee int./ext. rotation & $0.98(0.95-0.99)$ & 0.84 & 2.33 & $0.65(0.1-0.87)$ & 3.34 & 9.24 \\
Knee flex./ext. & $0.95(0.87-0.98)$ & 1.11 & 3.07 & $0.84(0.58-0.94)$ & 2.04 & 5.65 \\
Ankle ever./inver. & $0.96(0.90-0.98)$ & 0.77 & 2.12 & $0.04(-1.71-0.60)$ & 3.33 & 9.24 \\
Ankle dors./plan. flex. & $0.95(0.88-0.98)$ & 0.98 & 2.71 & $0.96(0.88-0.98)$ & 0.88 & 2.44 \\
\hline
\end{tabular}

Intrarater 1 - reliability in one measurement session without marker replacement; Intrarater 2 - reliability after marker replacement; ant. - anterior; post. - posterior; add. - adduction; abd. - abduction; int. - internal; ext. - external; flex. - flexion; exten. - extension; ever. - eversion; inver. - inversion; dors. - dorsal; plan. - plantar. 
Table 2. Intraclass correlation coefficient (ICC) (with 95\% confidence interval (CI)), standard error of measurement (SEM) and the smallest detectable differences (SDD) for kinematic parameters of pelvis and lower limb during single leg drop landing task

\begin{tabular}{lcccccc}
\hline & \multicolumn{3}{c}{ Intrarater 1 } & \multicolumn{3}{c}{ Intrarater 2 } \\
\hline & ICC $( \pm 95 \% \mathrm{CI})$ & SEM $\left({ }^{\circ}\right)$ & SDD $\left(^{\circ}\right)$ & ICC $( \pm 95 \% \mathrm{CI})$ & SEM $\left({ }^{\circ}\right)$ & SDD $\left(^{\circ}\right)$ \\
\hline Pelvic lift/drop & $0.93(0.82-0.97)$ & 0.77 & 2.14 & $0.95(0.85-0.98)$ & 0.88 & 2.43 \\
Pelvic rotation & $0.94(0.84-0.98)$ & 0.99 & 2.75 & $0.83(0.51-0.94)$ & 5.54 & 15.36 \\
Pelvic ant./post. tilt & $0.97(0.93-0.99)$ & 0.63 & 1.76 & $0.94(0.84-0.98)$ & 1.22 & 3.37 \\
Hip add./abd. & $0.94(0.84-0.98)$ & 1.01 & 2.79 & $0.95(0.85-0.98)$ & 0.88 & 2.43 \\
Hip int./ext. rotation & $0.99(0.98-1.00)$ & 0.78 & 2.15 & $0.90(0.71-0.97)$ & 2.50 & 6.92 \\
Hip flex./ext. & $0.98(0.94-0.99)$ & 0.71 & 1.97 & $0.96(0.89-0.99)$ & 1.45 & 4.03 \\
Knee add./abd. & $1.00(0.99-1.00)$ & 0.00 & 0.00 & $0.81(0.47-0.94)$ & 4.26 & 11.81 \\
Knee int./ext. rotation & $0.98(0.95-0.99)$ & 0.92 & 2.54 & $0.75(0.27-0.91)$ & 2.82 & 7.81 \\
Knee flex./ext. & $0.90(0.74-0.96)$ & 1.43 & 3.97 & $0.75(0.29-0.91)$ & 2.55 & 7.06 \\
Ankle ever./inver. & $0.96(0.90-0.99)$ & 0.78 & 2.15 & $0.25(-1.16-0.74)$ & 2.95 & 8.17 \\
Ankle dors./plan. flex. & $0.93(0.81-0.97)$ & 0.94 & 2.62 & $0.96(0.90-0.99)$ & 0.88 & 2.44 \\
\hline
\end{tabular}

Intrarater 1 - reliability in one measurement session without marker replacement; Intrarater 2 - reliability after marker replacement; ant. - anterior; post. - posterior; add. - adduction; abd. - abduction; int. - internal; ext. - external; flex. - flexion; exten. - extension; ever. - eversion; inver. - inversion; dors. - dorsal; plan. - plantar.

$[15,28]$ and single leg squat (ICC: $0.72-0.87)[14,15$, 28]. Herrinton et al. (2017) assessed hip adduction during single leg squat and single leg landing. The within-session ICC was $0.89-0.91$ and decreased between sessions (ICC: 0.79-0.86) [15]. Nakagawa et al. (2014) assessed reliability of pelvis and lower limb joints using an electromagnetic tracking system during the single-leg squat and stepping maneuver. The authors obtained good to excellent reliability within and between sessions (ICC: 0.86-1.00) during both tasks [30]. DiCesare et al. [10] assessed reliability of lower limb kinematics with the 3D method across 3 different institutions using the coefficients of multiple correlation $(\mathrm{CMC})$ during the single cross leg drop landing task. For lower limb kinematics the CMC was 0.62 to 0.97 . They also assessed trunk flexion (CMC: $0.96-0.98)$ and lateral trunk flexion (CMC: 0-0.38) [10].

Many similarities, such as high reliability within one measurement session and decrease of reliability replacement markers in the 3D method, were observed in relation to the papers of other researchers. This paper also evaluates pelvis kinematics, which seems to be related during single leg landing. Nakagawa et al. [30] assessed pelvis kinematics, but they used electromagnetic tracking [30]. Also, DiCesare et al. [10] assessed trunk sagittal and frontal movement. However, trunk kinematics is associated with both the pelvis and spine movement [10].

Both $2 \mathrm{D}$ and the 3D methods are reliable and can be used to assess kinematics during jumping, landing, cutting or running tasks to determine kinematic risk factors, e.g. for primary or secondary ACL injury. A parameter called the plane knee projection angle (FPPA) and hip adduction are often used in the assessment in the 2D method [14, 15, 28]. Application of the 3D method provides more data than the 2D method; in 3D dynamics knee valgus presents as a complex multi-joint and multi-planar phenomenon.

\section{Limitations}

This study assessed the reliability of measurements in one session and after marker replacement performed by one researcher. It is worth focusing in the future on assessing the reliability of measurements between days. Error associated with the placement of markers might not be the only factor affecting the reliability between sessions. It is also worth considering the assessment of reliability between raters to determine the error attributed to the researcher. If the landings had been made on a force plate, it would have given information on $3 \mathrm{D}$ forces during landing and thus about the landing technique, which can influence the results.

\section{Conclusions}

In the present study, the ICC values show excellent reliability of almost all kinematic parameters in one measurement session. Marker replacement is one of the factors influencing the measurement error decreasing the reliability of measurement. However, the reliability of a large number of the parameters was good and excellent. It should be noted that ankle eversion/inversion kinematics assessment requires special caution due to poor reliability. 
Applying the SEM and SDD values presented in this article, it provides useful information helping to determine whether the obtained values result from measurement error or are associated with individuals.

\section{Conflict of interest: Authors state no conflict of interest.}

\section{References}

1. Alenezi F., Herrington L., Jones P., Jones R. (2014) The reliability of biomechanical variables collected during single leg squat and landing tasks. J. Electromyogr. Kinesiol., 24: 718-721. DOI: 10.1016/j.jelekin.2014.07.007.

2. Alenezi F., Herrington L., Jones P., Jones R. (2016) How reliable are lower limb biomechanical variables during running and cutting tasks. J. Electromyogr. Kinesiol., 30: 137-142. DOI: 10.1016/j.jelekin.2016.07.001.

3. Allen M.K., Glasoe W.M. (2000) Metrecom measurement of navicular drop in subjects with anterior cruciate ligament injury. J. Athl. Train., 35: 403-406.

4. Barrios J.A., Heitkamp C.A., Smith B.P., Sturgeon M.M., Suckow D.W., Sutton C.R. (2016) Three-dimensional hip and knee kinematics during walking, running, and single-limb drop landing in females with and without genu valgum. Clin. Biomech., 31: 7-11. DOI: 10.1016/j. clinbiomech.2015.10.008.

5. Bell A.L., Brand R.A., Pedersen D.R. (1989) Prediction of hip joint centre location from external landmarks. Hum. Mov. Sci., 8: 3-16. DOI: 10.1016/0167-9457(89)90020-1.

6. Bell A.L., Pedersen D.R., Brand R.A. (1990) A comparison of the accuracy of several hip center location prediction methods. J. Biomech., 23: 617-621. DOI: 10.1016/0021-9290(90)90054-7.

7. Boden B.P., Sheehan F.T., Torg J.S., Hewett T.E. (2010) Noncontact anterior cruciate ligament injuries: Mechanisms and risk factors. J. Am. Acad. Orthop. Surg., 18: 1-8. DOI: 10.5435/00124635-201009000-00003.

8. Chappell J.D., Yu B., Kirkendall D.T., Garrett W.E. (2002) A comparison of knee kinetics between male and female recreational athletes in stop-jump tasks. Am.J. Sports Med., 30: 261-267. DOI: 10.1177/03635465020300021901.

9. DiCesare C.A., Bates N.A., Barber Foss K.D., Thomas S.M., Wordeman S.C., Sugimoto D., Roewer B.D., Medina McKeon J.M., Di Stasi S., Noehren B.W., Ford K.R., Kiefer A.W. (2015) Reliability of 3-Dimensional measures of single-leg cross drop landing across 3 different institutions: Implications for multicenter biomechanical and epidemiological research on ACL injury prevention. Orthop. J. Sport Med., 3: 1-9. DOI: $10.1177 / 2325967115617905$.

10. Ford K.R., Myer G.D., Hewett T.E. (2007) Reliability of landing 3D motion analysis: Implications for longitudinal analyses. Med. Sci. Sports Exerc., 39: 2021-2028. DOI: 10.1249/mss.0b013e318149332d

11. Fox A.S., Bonacci J., McLean S.G., Spittle M., Saunders N. (2014) What is normal? Female lower limb kinematic profiles during athletic tasks used to examine anterior cruciate ligament injury risk: A systematic review. Sport. Med., 44: 815-832.

12. Griffin L.Y., Agel J., Albohm M.J., Arendt E.A., Dick R.W., Garrett W.E., Garrick J.G., Hewett T.E., Huston L., Ireland M.L., Johnson R.J., Kibler W.B., Lephart S., Lewis J.L., Lindenfeld T.N., Mandelbaum B.R., Marchak P., Teitz C.C., Wojtys E.M. (2000) Noncontact anterior cruciate ligament injuries: risk factors and prevention strategies. J. Am. Acad. Orthop. Surg., 8: 141-150. DOI: 10.5435/00124635-200005000-00001.

13. Gwynne C.R., Curran S.A. (2014) Quantifying frontal plane knee motion during single limb squats: reliability and validity of 2-dimensional measures. Int. J. Sports Phys. Ther., 9: 898-906.

14. Herrington L., Alenezi F., Alzhrani M., Alrayani H., Jones R. (2017) The reliability and criterion validity of $2 \mathrm{D}$ video assessment of single leg squat and hop landing. J. Electromyogr. Kinesiol., 34: 80-85. DOI: 10.1016/j. jelekin.2017.04.004.

15. Herrington L., Munro A. (2010) Drop jump landing knee valgus angle; normative data in a physically active population. Phys. Ther. Sport, 11: 56-59. DOI: 10.1016/j. ptsp.2009.11.004.

16. Hewett T.E., Myer G.D., Ford K.R., Heidt R.S., Colosimo A.J., McLean S.G., Van Den Bogert A.J., Paterno M.V., Succop P. (2005) Biomechanical measures of neuromuscular control and valgus loading of the knee predict anterior cruciate ligament injury risk in female athletes: A prospective study. Am. J. Sports Med., 33: 492-501. DOI: 10.1177/0363546504269591.

17. Ishida T., Yamanaka M., Takeda N., Homan K., Koshino Y., Kobayashi T., Matsumoto H., Aoki Y. (2015) The effect of changing toe direction on knee kinematics during drop vertical jump: a possible risk factor for anterior cruciate ligament injury. Knee Surgery, Sport Traumatol. Arthrosc., 23: 1004-1009. DOI: 10.1007/s00167-013-2815-2.

18. Kobayashi H., Kanamura T., Koshida S., Miyashita K., Okado T., Shimizu T., Yokoe K. (2010) Mechanisms of the anterior cruciate ligament injury in sports activities: A twenty-year clinical research of 1,700 athletes. J. Sport Sci. Med., 9: 669-675.

19. Koga H., Nakamae A., Shima Y., Iwasa J., Myklebust G., Engebretsen L., Bahr R., Krosshaug T. (2010) Mechanisms for noncontact anterior cruciate ligament injuries: knee joint kinematics in 10 injury situations from female team handball and basketball. Am. J. Sports Med., 38: 2218-2225. DOI: 10.1177/0363546510373570.

20. Krosshaug T., Nakamae A., Boden B.P., Engebretsen L., Smith G., Slauterbeck J.R., Hewett T.E., Bahr R. (2007) 
Mechanisms of anterior cruciate ligament injury in basketball: Video analysis of 39 cases. Am. J. Sports Med., 35: 359-367. DOI: 10.1177/0363546506293899.

21. Laughlin W.A., Weinhandl J.T., Kernozek T.W., Cobb S.C., Keenan K.G., O’Connor K.M. (2011) The effects of single-leg landing technique on ACL loading. J. Biomech., 44: 1845-1851. DOI: 10.1016/j. jbiomech.2011.04.010.

22. Leppänen M., Pasanen K., Krosshaug T., Kannus P., Vasankari T., Kujala U.M., Bahr R., Perttunen J., Parkkari J. (2017) Sagittal plane hip, knee and ankle biomechanics and the risk of anterior cruciate ligament injury: A prospective study. Orthop. J. Sport Med., 5: 1-6. DOI: 10.1177/2325967117745487.

23. Malinzak R.A., Colby S.M., Kirkendall D.T., Yu B., Garrett W.E. (2001) A comparison of knee joint motion patterns between men and women in selected athletic tasks. Clin. Biomech., 16: 438-445. DOI: 10.1016/S0268-0033(01)00019-5.

24. McLean S.G., Walker K., Ford K.R., Myer G.D., Hewett T.E., Van Den Bogert A.J. (2005) Evaluation of a two dimensional analysis method as a screening and evaluation tool for anterior cruciate ligament injury. Br. J. Sports Med., 39: 355-362. DOI: 10.1136/ bjsm.2005.018598.

25. McNitt-Gray J.L. (1993) Kinetics of the lower extremities during drop landings from three heights. J. Biomech., 26: 1037-1046.

26. Mueske N.M., Vandenberg C.D., Pace J.L., Katzel M.J., Zaslow T.L., Padilla R.A., Wren T.A.L. (2018) Comparison of drop jump landing biomechanics and asymmetry among adolescents with hamstring, patellar and quadriceps tendon autografts for anterior cruciate ligament reconstruction. Knee, 25: 1065-1073. DOI: 10.1016/j. knee.2018.09.005.

27. Munro A, Herrington L, Carolan M (2012) Reliability of 2-dimensional video assessment of frontal-plane dynamic knee valgus during common athletic screening tasks. J Sport Rehabil 21:7-11. DOI: 10.1123/jsr.21.1.7

28. Munro A., Herrington L., Comfort P. (2017) The relationship between 2-dimensional knee-valgus angles during single-leg squat, single-leg-land and drop-jump screening tests. J. Sport Rehabil., 26: 72-77. DOI: 10.1123/ jsr.2015-0102.

29. Nakagawa T.H., Moriya É.T.U., Maciel C.D., Serrão F.V. (2014) Test-retest reliability of three-dimensional kinematics using an electromagnetic tracking system during single-leg squat and stepping maneuver. Gait Posture, 39: 141-146. DOI: 10.1016/j.gaitpost.2013.06.011.

30. Pappas E., Hagins M., Sheikhzadeh A., Nordin M., Rose D. (2007) Biomechanical differences between unilateral and bilateral landings from a jump: gender differences. Clin. J. Sport Med., 17: 263-268. DOI: 10.1097/ JSM.0b013e31811f415b.
31. Patrek M.F., Kernozek T.W., Willson J.D., Wright G.A., Doberstein S.T. (2011) Hip-abductor fatigue and singleleg landing mechanics in women athletes. J. Athl. Train., 46: 31-42. DOI: 10.4085/1062-6050-46.1.31.

32. Portney L.G., Watkins M.P. (2000) Foundations of Clinical Research Applications to Practice. Prentice Hall, Englewood Cliffs

33. Schurr S.A., Marshall A.N., Resch J.E., Saliba S.A .(2017) Two-dimensional video analysis is comparable to 3D motion capture in lower extremity movement assessment. Int. J. Sports Phys. Ther., 12: 163-172.

34. Sorenson B., Kernozek T.W., Willson J.D., Ragan R., Hove J. (2015) Two- and three-dimensional relationships between knee and hip kinematic motion analysis: singleleg drop-jump landings. J. Sport Rehabil., 24: 363-372. DOI: 10.1123 jsr.2014-0206.

35. Srinivasan D., Tengman E., Häger C.K. (2018) Increased movement variability in one-leg hops about 20 years after treatment of anterior cruciate ligament injury. Clin. Biomech., 53: 37-45. DOI: 10.1016/j. clinbiomech.2018.02.003.

36. Teng P.S.P., Kong P.W., Leong K.F. (2017) Effects of foot rotation positions on knee valgus during single-leg drop landing: Implications for ACL injury risk reduction. Knee, 24: 547-554. DOI: 10.1016/j.knee.2017.01.014.

37. Tran A.A., Gatewood C., Harris A.H.S., Thompson J.A., Dragoo J.L. (2016) The effect of foot landing position on biomechanical risk factors associated with anterior cruciate ligament injury. J. Exp. Orthop., 3: 1-7. DOI: 10.1186/s40634-016-0049-1.

38. Williams J.P. (1971) Aetiological classification of injuries in sportsmen. Br. J. Sport Med., 5: 228-230. DOI: 10.2106/JBJS.I.00610.

39. Wu G., Cavanagh P.R. (1995) ISB Recommendations in the Reporting for Standardization of Kinematic Data. J. Biomech., 28:1257-1261. DOI: 10.1016/0021-9290(95)00017-C.

40. Wu G., Siegler S., Allard P., Kirtley C., Leardini A., Rosenbaum D., Whittle M., D'Lima DD., Cristofolini L., Witte H., Schmid O., Stokes I. (2002) ISB recommendation on definitions of joint coordinate system of various joints for the reporting of human joint motion - part I: ankle, hip, and spine. J. Biomech., 35: 543-548. DOI: 10.1016/S0021-9290(01)00222-6.

41. Żuk M., Trzeciak M. (2016) Anatomical protocol for gait analysis: joint kinematics measurement and its repeatability. J. Theor. Appl. Mech., 55: 369-376. DOI: 10.15632/ jtam-pl.55.1.369.

\section{Received 29.04.2020 \\ Accepted 15.12.2020}

(c) University of Physical Education, Warsaw, Poland 